\title{
Clinical and Metabolic Correction of Pompe Disease by Enzyme Therapy in Acid Maltase-deficient Quail
}

\author{
Tateki Kikuchi, ${ }^{\ddagger}$ Helen Wen Yang, ${ }^{\star}$ Mark Pennybacker, ${ }^{\star}$ Nobutsune Ichihara, ${ }^{\ddagger}$ Makoto Mizutani, ${ }^{\S}$ Johan L.K. Van Hove, ${ }^{\star}$ \\ and Yuan-Tsong Chen* \\ *Department of Pediatrics, Duke University Medical Center, Durham, North Carolina 27710; ${ }^{\ddagger}$ Department of Animal Models for Human \\ Disease, National Institute of Neuroscience, NCNP, Tokyo 187, Japan; and ${ }^{\S}$ Laboratory of Animal Research Station, Nippon Institute for \\ Biological Science, Kobuchizawa, Yamanashi 408, Japan
}

\begin{abstract}
Pompe disease is a fatal genetic muscle disorder caused by a deficiency of acid $\alpha$-glucosidase (GAA), a glycogen degrading lysosomal enzyme. GAA-deficient (AMD) Japanese quails exhibit progressive myopathy and cannot lift their wings, fly, or right themselves from the supine position (flip test). Six 4-wk-old acid maltase-deficient quails, with the clinical symptoms listed, were intravenously injected with 14 or $4.2 \mathrm{mg} / \mathrm{kg}$ of precursor form of recombinant human GAA or buffer alone every 2-3 d for $18 \mathrm{~d}$ (seven injections). On day 18 , both high dose-treated birds $(14 \mathrm{mg} / \mathrm{kg})$ scored positive flip tests and flapped their wings, and one bird flew up more than $100 \mathrm{~cm}$. GAA activity increased in most of the tissues examined. In heart and liver, glycogen levels dropped to normal and histopathology was normal. In pectoralis muscle, morphology was essentially normal, except for increased glycogen granules. In sharp contrast, sham-treated quail muscle had markedly increased glycogen granules, multi-vesicular autophagosomes, and inter- and intrafascicular fatty infiltrations. Low dose-treated birds $(4.2 \mathrm{mg} / \mathrm{kg})$ improved less biochemically and histopathologically than high dose birds, indicating a dose-dependent response. Additional experiment with intermediate doses and extended treatment (four birds, $5.7-9 \mathrm{mg} / \mathrm{kg}$ for $45 \mathrm{~d}$ ) halted the progression of the disease. Our data is the first to show that an exogenous protein can target to muscle and produce muscle improvement. These data also suggest enzyme replacement with recombinant human GAA is a promising therapy for human Pompe disease. (J. Clin. Invest. 1998. 101:827-833.) Key words: acid $\alpha$-glucosidase - Pompe disease • acid maltase deficiency - Japanese quail • enzyme replacement therapy
\end{abstract}

\section{Introduction}

Replacement of the mutant protein for therapy of a genetic disease continues to be an active area of research and efficacy

Address correspondence to Y.-T. Chen, M.D., Ph.D., Division of Medical Genetics, Box 3528, Room 237, Bell Building, Trent Drive, Duke University Medical Center, Durham, NC 27710. Phone: 919684-2036; FAX: 919-684-8944; E-mail: chen0010@mc.duke.edu

Received for publication 16 September 1997 and accepted in revised form 8 December 1997.

J. Clin. Invest.

(C) The American Society for Clinical Investigation, Inc. 0021-9738/98/02/0827/07 \$2.00

Volume 101, Number 4, February 1998, 827-833

http://www.jci.org has been demonstrated in some inherited human diseases (1-4). To date, however, protein/enzyme therapy has not been shown to target to skeletal muscles, nor an efficacy demonstrated in any genetic muscle disease. Pompe disease is a fatal genetic muscle disorder caused by a deficiency of the glycogendegrading enzyme acid $\alpha$-glucosidase (GAA, also called acid maltase), ${ }^{1}$ resulting in lysosomal glycogen accumulation and muscle dystrophy (5). Patients with the most common form of Pompe disease present as infants (infantile form) and have extremely low $(<1 \%)$ GAA activity. Myopathy and hypertrophic cardiomyopathy are progressive and lead to death before two years of age (5). Patients with juvenile and adult forms of Pompe disease present with progressive skeletal muscle weakness and have some residual GAA activity.

Currently, there is no effective treatment for Pompe disease. Bone marrow transplantation has not been successful (6, 7). Previous attempts at enzyme replacement were ineffective because of an inadequate understanding of receptor-mediated endocytosis and an insufficient source of highly purified enzyme with appropriate targeting to muscle tissue (8-11). We aimed to target the affected organs, heart, and muscle based on mannose 6-phosphate (man 6-P) present in the precursor form of enzyme and man 6-P receptors present in these organs.

Recently, large quantities of recombinant human GAA (rhGAA) purified from the culture medium of Chinese hamster ovary $(\mathrm{CHO})$ cells transfected with human GAA became available $(12,13)$. Under optimal conditions, our GAA-transfected CHO cells secreted $91 \mathrm{mg} /$ liter of the precursor form of rhGAA into the medium every $48 \mathrm{~h}$ (12). Man 6-P blocked endocytosis of this precursor enzyme by primary fibroblasts derived from infantile Pompe disease patients, indicating man 6-P receptors mediated enzyme uptake. After intravenous injection of purified rhGAA into guinea pigs, GAA enzyme levels increase in liver, heart, and skeletal muscle, the organs primarily affected in Pompe disease (12 and our unpublished study).

To study the efficacy of man 6-P receptor targeted enzyme uptake in muscle and to evaluate its potential as a new enzyme replacement therapy, an appropriate animal model is needed. The only reported living animals with GAA deficiency are Shorthorn cattle $(14,15)$, Brahman cattle $(16)$, and a strain of Japanese quail $(17,18)$. No genetically engineered knockout mouse model for Pompe disease has yet been reported. Since cattle are too large for therapeutic experimentation with a limited source of recombinant enzyme, the acid maltase-deficient (AMD) Japanese quails are currently the only practical animal

1. Abbreviations used in this paper: AMD, acid maltase deficient; $\mathrm{CHO}$, Chinese hamster ovary; 4-MU, 4-methylumbelliferone- $\alpha$-Dglucoside; GAA, acid $\alpha$-glucosidase; man 6-P, mannose 6-phosphate; PAS, periodic acid-Schiff; rhGAA, recombinant human acid $\alpha$-glucosidase. 
model. The disease in AMD quails resembles the juvenile and adult forms of Pompe disease in humans in its late-onset, the presence of residual GAA activity (19), and the histologic changes in affected muscles $(20,21)$. The cation-independent man 6-P receptor, which is primarily responsible for receptormediated endocytosis of exogenous GAA, also has insulin-like growth factor II binding activity in mammals (for review see reference 22), but not in birds $(23,24)$. Despite differences in man 6-P receptors, the precursor form of rhGAA normalized GAA levels in primary fibroblasts and cultured myoblasts from AMD quails (25). Based on the success of these in vitro studies, we administered the precursor form of rhGAA to AMD quails intravenously and found significant improvements in the glycogen accumulation, GAA enzyme levels, tissue histology, and clinical symptoms.

\section{Methods}

Materials. Amyloglucosidase, man 6-P, 4-methylumbelliferone- $\alpha$-Dglucoside (4-MU), and its derivatives were obtained from Sigma Chemical Co. (St. Louis, MO). Reagents for glucose determination was from Roche Diagnostic Systems (Nutley, NJ). Neutralized methanol and formaldehyde fixative (UFIX) was obtained from Sakura Co. (Tokyo, Japan).

Production and evaluation of recombinant human acid $\alpha$-glucosidase. Recombinant human GAA was produced by transfected $\mathrm{CHO}$ cells and purified from the culture medium as previously described (12). Each batch of purified enzyme was analyzed for GAA enzyme activity using the 4-MU assay. Biological activity, or uptake, was assessed by adding purified enzyme to the culture medium of fibroblasts derived from Pompe disease patients and measuring the increase in GAA activity in the cells. The rhGAA used for the intravenous injection contained $2.7-6.5 \mathrm{mg} / \mathrm{ml} \mathrm{rhGAA}$ in phosphate buffered saline (PBS), $\mathrm{pH} 6.5$, and $>90 \%$ of the enzyme was $110 \mathrm{kD}$ precursor form.

AMD quail and enzyme administration. AMD quails (strain RWN) and normal quails (strain PNN) were obtained from the Nippon Institute for Biological Science Farm, Kobuchizawa, Yamahashi, Japan. All birds were cared for in accordance with institutional guidelines. AMD quails are able to reproduce and are maintained as a homozygous breeding population. In AMD quails, the age of onset of clinical symptoms varies among individual birds. At $3 \mathrm{wk}$ of age, each of the six male AMD quails selected, demonstrated the clinical symptoms of AMD in that they could not right themselves in a flip test and their wings were in a locked position when held upside down by their legs (Fig. 1). Two normal male birds of the same age, who were able to right themselves in a flip test and were able to flap their wings when held upside down, were used as controls.
The AMD quails were divided into three test groups and treatment started at 4 wk of age. The clinical effects of AMD were confirmed before treatment. The high dose group (two birds) received $14 \mathrm{mg}$ rhGAA per kilogram body weight per injection. A low dose group (two birds) received $4.2 \mathrm{mg}$ rhGAA per kilogram per injection. A sham-treated group (two birds) received an equivalent volume of PBS per injection. Enzyme (and PBS) was administered as a bolus intravenous injection via the jugular vein. Each test bird received a total of seven injections over a 16-d period. (The first three injections were administered every other day and the next four injections were spaced $3 \mathrm{~d}$ apart.) $2 \mathrm{~d}$ after the last injections (day 18), the birds were evaluated for signs of clinical improvement by the flip test and locked wings when held upside down. After the physical evaluation, the birds were killed and tissues were examined histologically for morphology and glycogen distribution, and biochemically for enzyme activity and glycogen content. Tissues from two normal birds were used as controls.

The second study consisted of four male AMD quails (age $4 \mathrm{wk}$, as above), which received a total of 16 injections of rhGAA, 2-3 d apart, over $45 \mathrm{~d}$. The first 12 doses of rhGAA were $5.7 \mathrm{mg} / \mathrm{kg}$ and the last four doses were $9.0 \mathrm{mg} / \mathrm{kg}$. Two male AMD quails were injected with PBS (sham treated) as described above.

Histopathological studies. To specifically preserve glycogen, tissues were fixed for $12 \mathrm{~h}$ with UFIX and then embedded in paraffin. Glycogen was visualized by staining the tissue sections with periodic acid-Shiff (PAS) and hematoxylin, and confirmed by loss of stainable PAS-positive granules after diastase digestion. The serial sections were also stained with hematoxylin and eosin for histopathological analysis.

Biochemical analysis. Enzyme activities of acid and neutral $\alpha$-glucosidase were assayed in a 96-well microtiter plate using 4-MU at $\mathrm{pH}$ 4.3 and $\mathrm{pH} 6.7$, respectively (26). Acid $\beta$-galactosidase was assayed using 4-methylumbelliferyl $\beta$-galactosidase as a substrate (27). The glycogen content of tissues was assayed by measuring the amount of glucose released from a boiled tissue homogenate after digestion with Aspergillus niger amyloglucosidase. The released glucose was measured by following the absorbency of NADH generated by a linked enzymatic assay with glucokinase and glucose 6-phosphate dehydrogenase (12). Total protein concentration was determined according to the Bradford method (28).

\section{Results}

rhGAA treatment improved weight gain. Over the $18 \mathrm{~d}$ of treatment, high dose $(14 \mathrm{mg} / \mathrm{kg})$ rhGAA treated quails continued to gain weight appropriately (average, $18 \mathrm{~g}$; versus normal quails, $23 \mathrm{~g}$ ) while sham treated quails gained only $10 \mathrm{~g}$ (Fig. 2). Low dose $(4.2 \mathrm{mg} / \mathrm{kg})$ rhGAA also improved weight gain (15.5 g) over the same treatment period (data not shown).
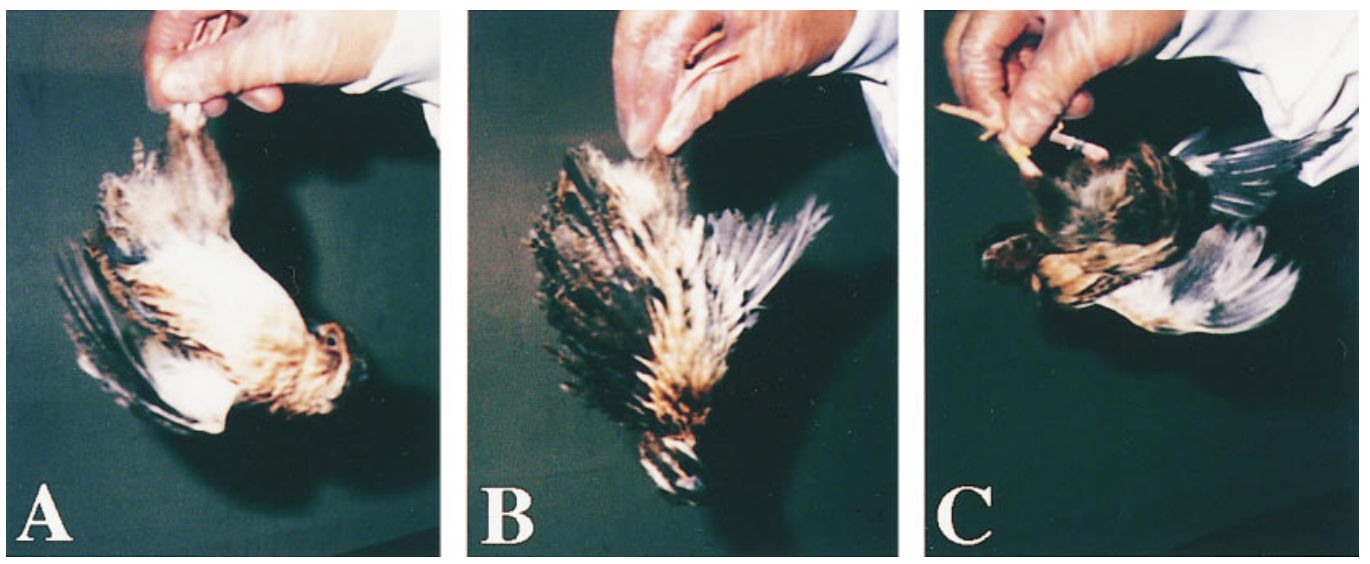

Figure 1. The wing motion of normal, sham-treated AMD, and high dose rhGAA-treated quails are shown. When held upside down by their legs, normal birds flap their wings $(A)$. The wings of AMD or sham-treated AMD birds (treated with PBS) are locked and unable to move $(B)$. The rhGAA-treated bird $(14 \mathrm{mg} / \mathrm{kg})$ is able to flap his wings $(C$, bird No. 03). 


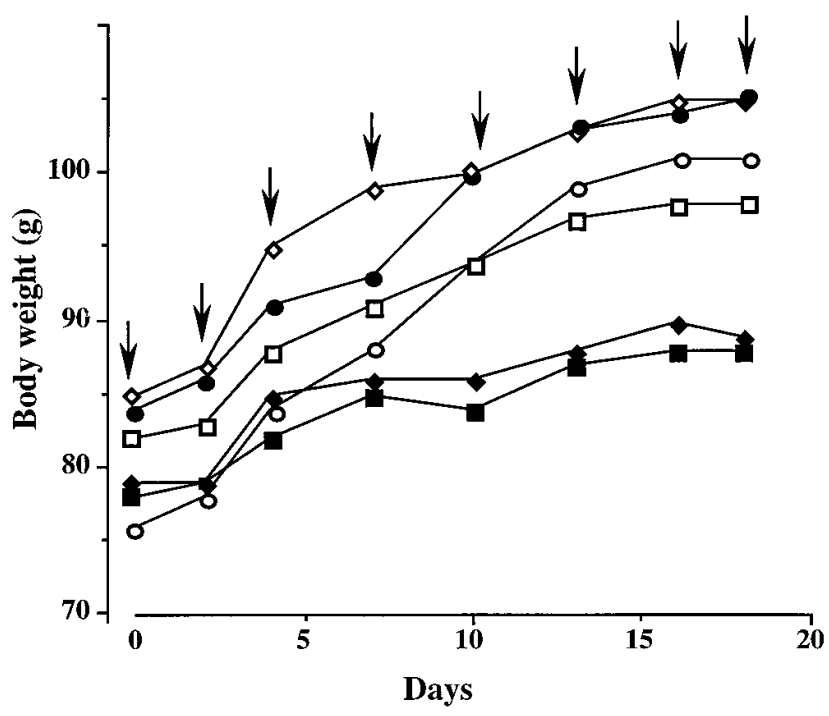

Figure 2. Weight gain of birds during the course of the 18-d study in which test animals received $14 \mathrm{mg} / \mathrm{kg}$ rhGAA. Open squares, rhGAA (bird No. 03); open diamonds, rhGAA (bird No. 20); black diamonds, PBS (bird No. 80); black squares, PBS (bird No. 92); black circles, normal quail (bird No. 26); open circles, normal quail (bird No. 69). Birds are numbered as in Table I. Arrows indicate time of the injection.

rhGAA treatment improved muscle performance and strength. Both birds that received the high dose showed signs of clinical improvement. They were able to right themselves in a flip test. One bird (No. 03) was able to perform this six times; the other bird was able to right itself once (normal birds can flip more than five times, sham-treated scored zero). Both birds were able to move their wings actively and both tried to rise when held upside down (Fig. $1 C$ ). In contrast, shamtreated or untreated birds had wings in the locked position
(Fig. $1 \mathrm{~B}$ ). Though not part of the experimental plan, one high dose bird (No. 03) surprised the investigators on day 18 when it flew up more than $100 \mathrm{~cm}$.

The birds that received the low dose of rhGAA and those sham treated (with PBS) were not able to right themselves in a flip test or move their wings from the locked position when suspended by their legs.

rhGAA treatment increased GAA activity in tissues. AMD quails had residual GAA activity 5-39\% of normal controls (Fig. 3). After rhGAA treatment, GAA activity increased in pectoralis muscle (a fast twitch muscle), anterior latissimus dorsi (ALD; a slow tonic muscle), liver, heart, spleen, kidney, lung, and testis. Spleen had the highest activity, which reached the level of normal controls. With the exception of pectoralis muscle, increased GAA activity appeared to be directly dose related, i.e., the higher dose gave higher activity. In the liver, heart, and kidney, the high dose resulted in GAA activity that was close to $50 \%$ of levels in normal quails. Spinal cord showed an increase of GAA activity with the high dose, but cerebrum, cerebellum, and brainstem exhibited little or no changes of activity, regardless of dose. As a control, we also measured $\beta$-galactosidase activity and found no significant difference among rhGAA treated, sham-treated, untreated AMD, and normal control quails.

rhGAA treatment improved histopathology and glycogen accumulation. The liver, heart, and skeletal (pectoralis) muscle were sectioned and stained with PAS reagent to visualize glycogen in the tissues. We chose to examine the pectoralis muscle because it is the most seriously affected skeletal muscle in AMD quail. The numbers of glycogen granules and severity of histopathological changes in the tissues were scored as +++ (very high $),++$ (high), + (moderate), or - (normal) compared with the levels observed in tissues from normal quails (Table I).

Pectoralis muscle from high dose-treated AMD quails (Fig. $4 C$ ) had considerably fewer glycogen granules than the sham-treated quails (Fig. $4 \mathrm{~B}$ ) but more than normal birds

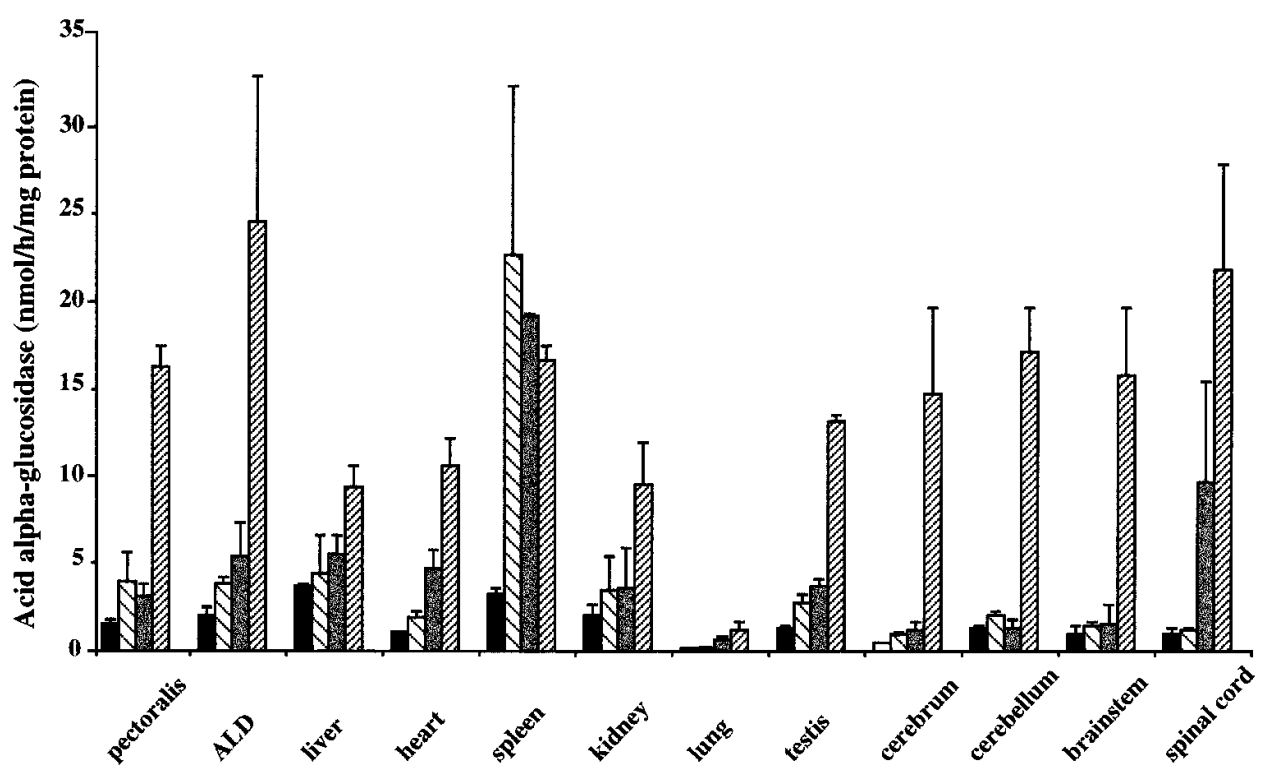

AMD+PBS $\triangle$ AMD+rhGAA (low dose)
AMD+rhGAA (high dose)
Figure 3. Tissue GAA activity in quails treated with rhGAA. Low dose was $4.2 \mathrm{mg} / \mathrm{kg}$ and high dose was $14 \mathrm{mg} / \mathrm{kg}$. $A L D$, anterior latissimus dorsi muscle. Data represents average \pm range of two quails in each group. GAA activity was measured in duplication with variation $<10 \%$. 
Table I. Histopathological Changes in Pectoralis Muscle, Liver, and Heart of Treated and Untreated AMD Quails

\begin{tabular}{|c|c|c|c|c|c|c|c|c|}
\hline \multirow[b]{2}{*}{ Quail } & \multicolumn{6}{|c|}{ AMD } & \multicolumn{2}{|c|}{ Normal } \\
\hline & \multicolumn{2}{|c|}{ PBS* } & \multicolumn{2}{|c|}{$\begin{array}{c}\text { rhGAA } \\
(14 \mathrm{mg} / \\
\mathrm{Kg})\end{array}$} & \multicolumn{2}{|c|}{$\begin{array}{c}\text { rhGAA } \\
(4.2 \mathrm{mg} / \\
\mathrm{Kg})\end{array}$} & \multicolumn{2}{|c|}{ None } \\
\hline Treatment Quail ID No. & 80 & 92 & 20 & 03 & 41 & 49 & 26 & 69 \\
\hline \multicolumn{9}{|l|}{ Pectoralis muscle } \\
\hline \multicolumn{9}{|l|}{ Muscle fibers } \\
\hline Glycogen granules & ++ & +++ & + & + & + & + & - & - \\
\hline Multiple vacuoles & +++ & ++ & - & - & + & - & - & - \\
\hline Necrosis & + & + & - & - & - & - & - & - \\
\hline Nuclear proliferation & ++ & ++ & - & - & + & - & - & - \\
\hline \multicolumn{9}{|l|}{ Connective tissue } \\
\hline Fatty infiltration & +++ & +++ & - & - & + & + & - & - \\
\hline \multicolumn{9}{|l|}{ Liver } \\
\hline Glycogen granules & +++ & +++ & - & - & + & - & - & - \\
\hline \multicolumn{9}{|l|}{ Heart } \\
\hline Glycogen granules & +++ & +++ & - & - & + & + & - & - \\
\hline
\end{tabular}

Glycogen granules and severity of pathological changes were scored as normal $(-)$, moderate $(+)$, high $(++)$, or very high $(+++) . * P B S$, PBS as sham treatment.

(Fig. $4 A$ ). The skeletal muscle morphology of rhGAA-treated AMD quails was significantly improved compared with shamtreated AMD quails. The fiber necrosis and nuclear proliferation seen in sham-treated birds, indicators of severe muscle damage and regeneration, were absent in rhGAA-treated birds. Multiple vacuoles containing multi-vesicular autophagosomes (confirmed by electron microscopy, data not shown), and inter- and intrafascicular fatty infiltrates observed in sham-treated AMD quails' skeletal muscle were also absent in treated birds. This was associated with a much more uniform size of the myofiber bundles.

Glycogen levels of liver and heart were most dramatically reduced in the rhGAA high dose birds. Fig. $4, D-F$ are sections of liver stained with PAS from normal, AMD shamtreated, and AMD high dose rhGAA-treated quails. Liver tissue from high dose-treated AMD quails (Fig. $4 F$ ) were indistinguishable from normal quail liver (Fig. $4 D$ ). Liver tissue from sham-treated AMD quails showed very high levels of glycogen throughout (Fig. 4 E). Similarly, the heart from high dosetreated AMD quails was indistinguishable from normal quails (Fig. 4, $I$ and $G$, respectively). Like the liver, hearts from sham-treated AMD quails showed very high levels of glycogen (Fig. $4 \mathrm{H}$ ). The heart of the treated birds was soft and pliable to the touch, like a normal heart. Hearts from sham or untreated AMD birds were stiff and hard.

In the low dose group, liver had almost normal levels of glycogen (Table I). The amount of glycogen in the heart, though still excessive, was noticeably reduced (scored as + , moderate) compared with the sham-treated birds (scored as +++ , very high). The low dose of rhGAA was also effective in reducing the amounts of glycogen found in skeletal (pectoralis) muscle. Histopathology of pectoralis muscle showed significant improvements in the reduction of fatty infiltration, ne- crosis, and nuclear proliferation compared with sham-treated AMD birds.

The biochemical analysis of glycogen content (Fig. 5) was consistent with the histopathology. Of note, glycogen was reduced to normal levels in the liver and heart of rhGAAtreated quails, while glycogen was reduced proportional to the dose in pectoralis muscle of treated birds.

Extended treatment with rhGAA. A second group of male AMD quails (four birds, age 4 wk with clinical symptoms described previously) were treated every 2-3 d, for a total of $45 \mathrm{~d}$, with $5.7 \mathrm{mg} / \mathrm{kg}$ rhGAA (first 12 doses) and $9.0 \mathrm{mg} / \mathrm{kg}$ rhGAA (last four doses), doses intermediate to the high and low amounts used in the first study. As before, two AMD quails were sham treated with PBS. At this intermediate dose, the histopathology of the rhGAA-treated birds was dramatically improved compared with sham-treated birds (data not shown). The histopathology of the liver and heart of rhGAA-treated birds was normal except for a small number of glycogen granules in the heart. The pectoralis muscle fiber morphology was normal except for increased numbers of glycogen granules and small amount of fatty infiltration. This intermediate dose dramatically reduced the fiber necrosis, nuclear proliferation, multiple vacuoles, and fatty infiltrates seen in sham-treated birds and, in two enzyme-treated birds, none of these degenerative changes were seen. On the other hand, more advanced muscle fiber degeneration and pathological changes were noted in the pectoralis muscle of $45 \mathrm{~d}$ sham-treated birds than $18 \mathrm{~d}$ (Fig. 4 I), presumably because of the increased age and advanced stage of the disease.

Despite the significantly improved histopathology of affected tissues, the intermediate dose rhGAA-treated AMD quails did not show clinical improvement in muscle strength and were not able to complete the flip test, flap their wings, or fly.
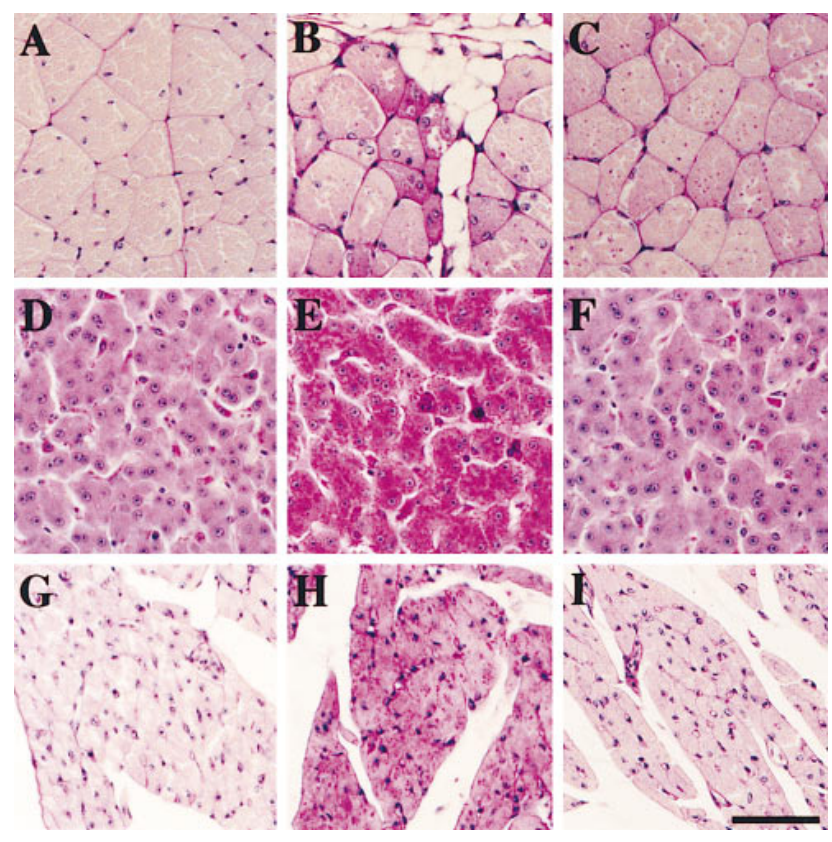

Figure 4. Pectoralis muscle $(A-C)$, liver $(D-F)$, and heart $(G-I)$ sections stained with PAS from normal $(A, D$, and $G)$, AMD shamtreated $(B, E$, and $H)$, and AMD high dose rhGAA-treated $(C, F$, and $I$ ) quail. Bar, $50 \mu \mathrm{m}$. 


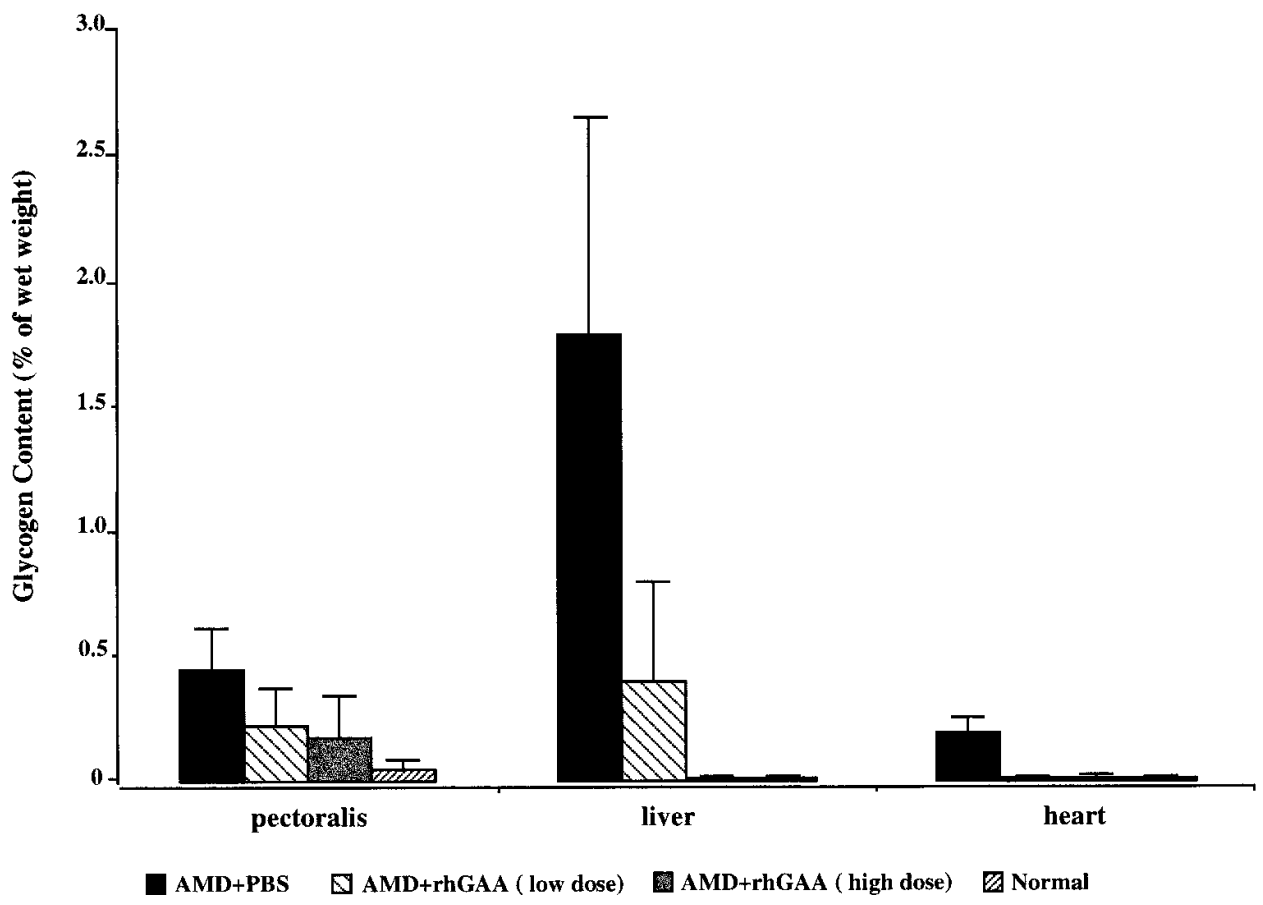

Figure 5. Glycogen content in quail treated with rhGAA. Low dose was $4.2 \mathrm{mg} / \mathrm{kg}$ and high dose was $14 \mathrm{mg} /$ $\mathrm{kg}$. Glycogen was measured by the release of glucose after digestion with $A$. niger amyloglucosidase. Assay was done in duplicate with $<15 \%$ variation. Data represents average \pm range of two quails in each group.

\section{Discussion}

AMD quails show progressive muscle weakness that begins at 3-4 wk after hatching and manifests in an inability to lift their wings, fly, or right themselves from the supine position. Weight gain is poor and joint contractures gradually develop. The birds become progressively emaciated and die before 18 mo of age (21). The average normal quail life span is 30 mo. Pectoralis muscle is the most severely affected tissue. The histopathological changes in the muscle start with glycogen accumulation and deposition of PAS-positive glycogen granules, then vacuoles containing multi-vesicular autophagosomes become evident. Gradually, evidence of muscle degeneration (necrotic fibers) and regeneration (nuclear proliferation) are apparent and muscle fiber is replaced by fatty tissue. These pathological changes arrested in rhGAA-treated quails in a dose-dependent manner. Increased GAA activity was seen in all tissues examined except the central nervous system. Western blot analysis using human GAA-specific antibody showed that increased GAA activity was indeed due to uptake of the human enzyme (data not shown). However, it was difficult to accurately determine the contribution of rhGAA taken up by the cells relative to endogenous GAA, due to the high residual enzyme activity in quail and possible sequestering of the rhGAA in the capillary endothelium. The unexpectedly high GAA activity in the spinal cord may reflect the latter effect. Along with histopathological and biochemical improvements, muscle strength improved as evidenced by positive flip scores, wing flapping, and flying. The ability to fly requires strength and coordination of many muscle groups of which the pectoralis muscle is the most critical. These data demonstrate that rhGAA treatment can reverse the muscle dystrophic process in its most significant pathology and symptomatology in AMD quails. The continuous weight gain observed in all birds treated with rhGAA indicates that the rhGAA was not toxic or detrimental to the overall health of the birds.
Protein/enzyme replacement is a potential therapy for genetic diseases, and its efficacy has been demonstrated in some human disorders including adenosine deaminase deficiency (1), $\alpha 1$-antitrypsin deficiency (2), hemophilia (3), and Gaucher disease (4). None of these diseases, however, affect the muscles. Furthermore, protein/enzyme therapy has not been shown to target to skeletal muscle, nor has efficacy been demonstrated in any genetic muscle disease. The discovery of cell surface receptors that mediate delivery of lysosomal enzymes to target tissues has given promise to this approach for treatment of lysosomal storage diseases. An effective therapy is now available for Gaucher disease (4) and some success has been demonstrated in animal models of mucopolysacharidoses (29-31) and other lysosomal storage diseases, such as Fabry's disease (32). However, muscle is not an affected organ in these disorders. Our data is the first to show that an exogenous enzyme can target to muscle and produce muscle improvement. This is the first successful attempt at developing a therapy for treatment of a genetic disorder affecting muscle.

Man 6-P receptors have a wide tissue distribution. They are abundant in heart, kidney, and thymus; intermediate in liver, lung, spleen, testis, and ovary; and low but present in muscle and brain $(33,34)$. Although we do not know the exact mechanism by which exogenous rhGAA improves clinical symptoms and histopathology of AMD quails, it is likely, from the evidence of our in vitro data $(12,25)$, that rhGAA is taken up by the muscle cells via man 6-P receptor mediated endocytosis. However, it is also possible that uptake of rhGAA by muscle is mediated by other carbohydrate receptors.

AMD quails resemble human juvenile or adult form of Pompe disease in its clinical course, residual enzyme activity, organ involvement, and histology findings. AMD quail, unlike human infantile Pompe disease, do not develop cardiomyopathy or dysfunction, although glycogen accumulates in the quail's heart. Because we found that exogenous rhGAA dramatically improved the clinical symptoms and corrected glyco- 
gen accumulation in the heart, we anticipate that rhGAA enzyme replacement is not only a potential therapy for juvenile and adult forms of Pompe disease, but also for infantile Pompe disease. It should be noted, though, that glycogen accumulation is also seen in the neurons of infantile disease patients, particularly in anterior horn cells of the spinal cord. There are, however, no clinical symptoms such as mental impairment, neurological deficits, or motor neuropathy evident in these patients (5).

In this investigation, the therapeutic effects were demonstrated in AMD quails treated with rhGAA $(4.2-14 \mathrm{mg} / \mathrm{kg})$ at 2-3 d intervals. Given that a single dose of rhGAA corrected intracellular GAA and glycogen in human Pompe disease fibroblasts to normal levels for $7 \mathrm{~d}(12)$, it is possible that less frequent dosing would also be effective. This remains to be tested. Extrapolation of dose for surface area adjustment would suggest that one eighth of quail dose could be effective in humans (35). Furthermore, in vitro quail fibroblasts and muscle cells require a higher dose of rhGAA than human Pompe disease fibroblasts to raise the intracellular GAA to normal levels (25). This may reflect differences in the number and ability of the man 6-P receptor in the two species to facilitate rhGAA endocytosis. In fact, all of these findings suggest that a lower and less frequent dose would be effective in humans.

The full-length quail GAA cDNA recently was isolated from a cDNA library derived from the liver of a Japanese quail. Compared with normal quails, the levels of GAA mRNA were markedly reduced in muscle, liver, heart, and brain of AMD quails, which suggests that the GAA deficiency in AMD quails is due to a lack of GAA mRNA (36). The residual GAA activity in the AMD quail is likely due to the presence of other $\alpha$-glucosidases $(19,36)$. Human GAA has only $52 \%$ amino acid sequence homology to the quail GAA (36). As expected from interspecies antigenicity, antibody was detected (data not shown). The lack of additional muscle improvement in the second study, which extended the treatment to 45 days, could be due to the antibody response that reduced the effectiveness of the therapy in these quails.

In conclusion, we have shown that AMD quails are suitable animals to test the efficacy of enzyme replacement or, possibly, gene therapy for human Pompe disease. The clinical histopathological and biochemical improvements of affected quails support the notion that enzyme replacement with rhGAA is a promising therapy for human Pompe disease.

\section{Acknowledgments}

The authors thank Letealia Oliver, Hisae Kikuchi, and Kazuko Akama for their expert technical assistance, and Quinn Sadler for her expert secretarial assistance.

This investigation was supported by grants from the Muscular Dystrophy Association of America and Japan Health Science Foundation, and a grant from Synpac Pharmaceuticals Ltd., and by a gift from the Acid Maltase Deficiency Association.

\section{References}

1. Hershfield, M.S., R.H. Buckley, M.L. Greenberg, A.L. Melton, R. Schiff, C. Hatem, J. Kurtzberg, M.L. Markert, R.H. Kobayashi, et al. 1987. Treatment of adenosine deaminase deficiency with polyethylene glycol-modified adenosine deaminase. N. Engl. J. Med. 316:589-596.

2. Wewers, M.D., M.A. Casolaro, S.E. Sellers, S.C. Swayze, K.M. McPhaul,
J.T. Wittes, and R.G. Crystal. 1987. Replacement therapy for $\alpha$-antitrypsin deficiency associated with emphysema. $N$. Engl. J. Med. 316:1055.

3. Kazazian, H.H., E.G.D. Tuddenham, and S.E. Antonarakis. 1995. Hemophilia and parahemophilia: deficiencies of coagulation factors VIII and V. In The Metabolic and Molecular Basis of Inherited Disease, 7th edition. C.R. Scriver, A.L. Beaudet, W.S. Sly, D. Valle, editors. McGraw-Hill, Inc., New York. 3341-3267.

4. Barton, N.W., F.S. Furbish, G.J. Murray, M. Garfield, and R.O. Brady. 1990. Therapeutic response to intravenous infusions of glucocerebrosidase in a patient with Gaucher disease. Proc. Natl. Acad. Sci. USA. 87:1913-1916.

5. Hirschhorn, R. 1995. Glycogen storage disease type II: acid $\alpha$-glucosidase (acid maltase) deficiency. In The Metabolic and Molecular Basis of Inherited Disease, 7th edition. C.R. Scriver, A.L. Beaudet, W.S. Sly, D. Valle, editors. McGraw-Hill, Inc., New York. 2443-2464

6. Watson, J.G., D. Gardner-Medwin, M.E. Goldfinch, A.D.J. Pearson 1986. Bone marrow transplantation for glycogen storage disease type II (Pompe's disease). N. Engl. J. Med. 314:385.

7. Harris, R.E., D. Hannon, C. Vogler, and G. Hug. 1986. Bone marrow transplantation in type IIa glycogen storage disease. In Bone Marrow Transplantation for Treatment of Lysosomal Storage Diseases. W. Krivit and N.W. Paul, editors. Alan R. Liss, New York. 119-132.

8. Hug, G., and W.K. Schubert. 1967. Hepatic lysosomes in Pompe's disease: disappearance during glucosidase administration. J. Clin. Invest. 46:1073.

9. Lauer, R.M., T. Mascarinas, A.S. Racela, A.M. Diehl, and B.I. Brown. 1968. Administration of a mixture of fungal glucosidases to a patient with type II glycogenosis (Pompe disease). Pediatrics. 42:672.

10. de Barsy, T., P. Jacquemin, F. Van Hoof, and H.-G. Hers. 1973. Enzyme replacement in Pompe disease: an attempt with purified human acid $\alpha$-glucosidase. Birth Defects Orig. Artic. Ser. 9:184-190.

11. Williams, J.C., and A.K. Murray. 1980. Enzyme replacement in Pompe disease with an alpha glucosidase low-density lipoprotein complex. In Enzyme Therapy in Genetic Diseases: II. Alan R. Liss, New York. 415-423.

12. Van Hove, J.L.K., H.W. Yang, J.-Y. Wu, R.O. Brady, Y.-T. Chen. 1996. High level production of recombinant human lysosomal acid $\alpha$-glucosidase in Chinese hamster ovary cells which targets to heart muscle and corrects glycogen accumulation in fibroblasts from patients with Pompe disease. Proc. Natl. Acad. Sci. USA. 93:65-70.

13. Fullar, M., A. Van Der Ploeg, A.J.J. Reuser, D.S. Anson, and J.J. Hopwood. 1996. Isolation and characterization of a recombinant precursor form of lysosomal acid alpha-glucosidase. Eur. J. Biochem. 234:903-909.

14. Richards, R.B., J.R. Edwards, R.D. Cook, and R.R. White. 1977. Bovine generalized glycogenosis. Neuropathol. Appl. Neurobiol. 3:45-56.

15. Howell, J.M., P.R. Dorling, R.D. Cook, W.F. Robinson, S. Bradley, J.M. Gawthorne. 1981. Infantile and late onset form of generalised glycogenosis type II in cattle. J. Pathol. 134:267-277.

16. O'Sullivan, B.M., P.J. Healy, R.E. Fraser, R.E. Nieper, R.J. Whittle, and C.A. Sewell. 1981. Generalized glycogenosis in Brahman cattle. Aust. Vet. J. 57: 227-229.

17. Murakami, H., A. Takagi, S. Nanaka, S. Ishiura, and H. Sugita. 1980. Glycogenosis II in Japanese quails. Exp. Anim. (Tokyo). 29:475-485.

18. Murakami, H., A. Takagi, I. Nonaka, S. Ishiura, H. Sugita, and M. Mizutani. 1982. Type 2 glycogen storage disease in Japanese quail. In Muscular Dystrophy. S. Ebashi, editor. University of Tokyo Press, Tokyo. 37-48.

19. Usuki, F., S. Ishiura, and H. Sugita. 1986. Developmental study of $\alpha$-glucosidase in Japanese quails with acid maltase deficiency. Muscle Nerve. 9:537-543.

20. Higuchi, I., I. Nonaka, F. Usuki, S. Ishiura, and H. Sugita. 1987. Acid maltase deficiency in the Japanese quail; early morphological event in skeletal muscle. Acta. Neuropathol. 73:32-37.

21. Fujita, T., I. Nonaka, and H. Sugita. 1991. Japanese quail and human acid maltase deficiency: a comparative study. Brain Dev. 13:247-255.

22. Kornfeld, S. 1992. Structure and function of the mannose 6-phosphate/ insulin-like growth factor II receptors. Аnnu. Rev. Biochem. 61:307-330.

23. Canfield, W.M., and S. Kornfeld. 1989. The chicken liver cation-independent mannose 6-phosphate receptor lacks the high affinity binding site for insulin-like growth factor II. J. Biol. Chem. 264:7100-7103.

24. Yang, Y.W.-H., A.R. Robbins, S.P. Nissley, M. Rechler. 1991. The chick embryo fibroblast cation-independent mannose 6-phosphate receptor is functional and immunologically related to the mammalian insulin-like growth factor-II (IGF-II)/man 6-P receptor but does not bind IGF-II. Endocrinology. 128: 1177-1189.

25. Yang, H.W., M. Mizutani, Y. Hagiwara, T. Kikuchi, J.L.K. Van Hove, and Y.T. Chen. 1996. Recombinant human acid $\alpha$-glucosidase corrects acid $\alpha$-glucosidase deficient human fibroblasts, quail fibroblasts and quail myoblasts. Am. J. Hum. Genet. 59:1197A.

26. Reuser, A.J.J., J.F. Koster, A. Hoogeveen, and H. Galjaard. 1978. Biochemical, immunological, and cell genetic studies in glycogenosis type II. Am. J. Hum. Genet. 30:132-143.

27. Wenger, D.A., and C. Williams. 1991. Screening for lysosomal disorders. In Techniques in Diagnostic Human Biochemical Genetics. A Laboratory Manual. F.A. Hommes, editor. Wiley-Liss, Inc., New York. 587-617.

28. Bradford, M.M. 1976. A rapid and sensitive method for the quantitation of microgram quantities of protein using the principle of protein-dye binding. Anal. Biochem. 72:248-254. 
29. Vogler, C., M. Sands, A. Higgins, B. Levy, J. Grubb, E.H. Birkemeier, and W.S. Sly. 1993. Enzyme replacement with recombinant $\beta$-glucuronidase in the newborn mucopolysaccharidosis type VII mouse. Pediatr. Res. 34:837-840.

30. Kakkis, E.D., M.F. McEntee, A. Schmidtchen, E.F. Neufeld, D.A. Ward, R.E. Gompf, S. Kania, C. Bedolla, S.-L. Chien, and R.M. Shull. 1996. Long-term and high-dose trials of enzyme replacement therapy in the canine model of mucopolysaccharidosis I. Biochem. Mol. Med. 58:156-167.

31. Crawley, A.C., K.H. Niedzielski, E.L. Isaac, R.C. Davey, S. Byers, J.J. Hopwood. 1997. Enzyme replacement therapy from birth in a feline model of mucopolysaccharidosis type VI. J. Clin. Invest. 99:651-662.

32. Ioannou, Y.A., K.M. Zeidner, B. Friedman, and R.J. Desnick. 1996. Fabry disease: enzyme replacement therapy in $\alpha$-galactosidase A-deficient mice. Am. J. Hum. Genet. 59:A71.
33. Wenk, J., A. Hille, K. von Figura. 1991. Quantitation of Mr 46000 and Mr 300000 mannose 6-phosphate receptors in human cells and tissues. Biochem. Int. 23:723-732.

34. Funk, B., U. Kessler, W. Eisenmenger, A. Hansmann, H.J. Kolb, and W. Kiess. 1992. Expression of the insulin-like growth factor-II/mannose 6-phosphate receptor in multiple human tissues during fetal life and early infancy. $J$. Clin. Endocrinol. Metab. 75:424-431.

35. Schmidt-Nielsen, K. 1984. Scaling: why is animal size so important? Cambridge University Press, Cambridge. $81 \mathrm{pp}$.

36. Kunita, R., O. Nakabayashi, J.Y. Wu, Y. Hagiwara, M. Mizutani, M.F. Pennybacker, Y.T. Chen, and T. Kikuchi. 1998. Molecular cloning of acid $\alpha$-glucosidase cDNAs of Japanese quail (Coturnix coturnix japonica) and the lack of its mRNA in acid maltase deficient quails. Biochem. Biophys. Acta. In press. 